\title{
TNF- $\alpha$ Induces Actin Cytoskeleton Reorganization in Glomerular Epithelial Cells Involving Tyrosine Phosphorylation of Paxillin and Focal Adhesion Kinase
}

\author{
S. B. Koukouritaki, ${ }^{1}$ E. A. Vardaki, $^{2}$ E. A. Papakonstanti, ${ }^{1}$ \\ E. Lianos, ${ }^{3}$ C. Stournaras, ${ }^{1}$ and D. S. Emmanouel ${ }^{2}$ \\ Departments of ${ }^{1}$ Biochemistry and ${ }^{2}$ Nephrology, University of Crete \\ School of Medicine, Heraklion, Greece \\ ${ }^{3}$ Department of Medicine, Nephrology Division, Medical College of \\ Wisconsin, Milwaukee, Wisconsin, U.S.A.
}

Accepted April 3, 1999.

\begin{abstract}
Glomerular permeability for macromolecules depends partially on proper attachment of the glomerular epithelial cells (GEC) to the glomerular basement membrane (GBM). The latter requires integrity of the actin cytoskeleton, which in turn is regulated by specific actin-associated proteins. Since several glomerulopathies characterized by heavy proteinuria are associated with increased glomerular tumor necrosis factor $\alpha$ (TNF- $\alpha$ ) expression, we studied the interaction of TNF- $\alpha$ with the actin cytoskeleton of cultured rat GEC. Incubation of GEC with $10 \mathrm{ng} / \mathrm{ml}$ TNF- $\alpha$ for variable time periods ranging from $15 \mathrm{~min}$ to $24 \mathrm{hr}$ demonstrated a marked accentuation and redistribution of actin microfilaments, as shown by direct fluorescence analysis and confocal laser scanning microscopy. Quantitative biochemical determination of the G/total-actin ratio confirmed the above observations. Indeed, this ratio was significantly reduced, indicating substantial polymerization of G-actin and formation of F-actin. Concurrently, TNF- $\alpha$ rapidly induced tyrosine phosphorylation of both paxillin and focal adhesion ki-
\end{abstract}

nase, without affecting the expression levels of these two proteins. In addition, tyrosine phosphorylation of vinculin became evident, indicating involvement of this focal adhesion marker in the observed actin reorganization. Inhibition of tyrosine phosphorylation by genistein prevented the reorganization of the actin cytoskeleton by TNF- $\alpha$. We conclude that TNF- $\alpha$ induces substantial reorganization of actin cytoskeleton and focal adhesions. These effects occur simultaneously, with a prompt TNF$\alpha$-induced tyrosine phosphorylation of paxillin and focal adhesion kinase, indicating that these proteins, known to regulate actin polymerization and formation of focal adhesions, may be directly involved in the mechanism controlling the observed actin redistribution. These findings suggest that the observed TNF- $\alpha$-actin cytoskeleton interactions may relate to the pathogenesis of glomerulopathies with heavy proteinuria, in which increased glomerular expression of TNF- $\alpha$ is associated with disturbances in the attachment of podocytes to the GBM.

\section{Introduction}

Glomerular epithelial cells (GEC), also referred to as podocytes, adhere to their substratum, which is the glomerular capillary basement membrane

Address correspondence and reprint requests to: Prof. D. S. Emmanouel, Department of Nephrology, School of Medicine, P.O. Box 1352, University of Crete, GR-71110 Heraklion, Greece. Phone: 308139 2221; Fax: 3081392605
(GBM) in a highly specialized manner. Contact of GEC to the GBM is made through cytoplasmic extensions known as foot processes. These, along with the slit pores and the slit-pore diaphragms, are part of the physiologic barrier of the glomerular capillary wall to macromolecules. Perturbations in GEC contact to the GBM may result in increased glomerular capillary permeability to proteins (pro- 
teinuria). This occurs in certain glomerulopathies such as minimal change disease, focal segmental glomerulosclerosis, and membranous nephropathy. In these forms of injury, electron microscopic examination of GEC reveals distorted contact between these cells and the GBM, referred to as footprocess effacement, fusion, or flattening (1).

Cell adhesion to substrata is a tightly regulated process involving the actin cytoskeleton and cytoskeletal regulatory proteins $(2,3)$. These major components of the cytoskeleton are organized in a highly ordered manner and play essential roles in the maintenance of cell shape and morphology. In addition, however, many aspects of cellular physiology seem to be actively modulated by changes in actin cytoskeleton dynamics, which involve reorganization and restructuring of the filaments. Such morphological alterations are principally induced by rapid modulations in the polymerization dynamics of microfilaments in response to external stimuli, including hormones, growth factors, and ions (4-8). The mechanisms controlling the cytoskeletal equilibrium dynamics may include activation of proteins that regulate actin polymerization (9) protein kinases or phosphatases (10), changes in cAMP concentrations (4), and activation of small GTPases of the Rho family (11-13). Thus the actin cytoskeleton seems to act both as a sensor and as a transducer of cellular signals.

The molecular basis of abnormalities of GEC contact with the GBM in these glomerulopathies is unknown and is likely to involve cytoskeletal proteins that regulate assembly of the actin cytoskeleton. Factors that can cause changes in expression of these proteins include the cytokines, which, by activating postreceptor biochemical events leading to assembly or disassembly of microfilaments, may variably affect the cytoskeletal organization, causing changes in cell shape and in cell-matrix interactions (14).

Recent evidence suggests that an unidentified cytokine-like factor may cause GEC injury in minimal change disease and focal segmental glomerulosclerosis $(15,16)$. Moreover, enhanced synthesis and release of TNF- $\alpha$ is found in GEC but not in glomerular endothelial or mesangial cells in human membranous nephropathy (17). The role of this selective overproduction of TNF- $\alpha$ by GEC in mediating proteinuria in membranous nephropathy is unknown. TNF- $\alpha$ can cause changes in the assembly of the cytoskeleton and in expression of specific cytoskeletal proteins that regulate cell adhesion $(18,19)$. It is therefore possible that TNF- $\alpha$-induced changes in the cytoskeletal assembly of GEC may perturb their contact to GBM, thereby increasing permeability of the glomerular capillary to protein.

In this work, we used morphological and biochemical approaches to study modulations in actin cytoskeleton organization and focal adhesions that are induced by TNF- $\alpha$. Moreover, we assessed quantitatively the effect of TNF- $\alpha$ on actin microfilament polymerization dynamics as a marker of changes in GEC cytoskeletal assembly. Finally, in an effort to explore the mechanism responsible for the alterations in the actin cytoskeleton induced by TNF- $\alpha$, we studied the effects of this cytokine on the expression levels and tyrosine phosphorylation of paxillin and focal adhesion kinase (FAK), two proteins that participate in the regulation of G-actin polymerization and that are intimately involved in podocyte attachment to their underlying substratum.

\section{Materials and Methods}

\section{Reagents}

Culture media, DME low glucose, HAM's F-12, HEPES, $\mathrm{NaHCO}_{3}$, L-glutamine, insulin-transferrin-selenium (ITS), penicillin-streptomycin, $\mathrm{Nu}$ serum, and collagen I were from GIBCO (Life Technologies, Bethesda, MD). Bovine serum albumin (BSA), DNase I, DNA, cytochalasin B and protein $G$ Sepharose, and monoclonal anti-vinculin and anti-talin antibodies were from Sigma (St. Louis, MO). Recombinant rat and human TNF- $\alpha$ were from R\&D Systems (Minneapolis, $\mathrm{MN}$ ), and rhodamine-phalloidin was purchased from Molecular Probes (Eugene, OR). Monoclonal antibodies against FAK and phosphotyrosine were purchased from Upstate Biotechnology (Lake Placid, NY). The antiphosphotyrosine horseradish peroxidase conjugate (PTO4P) was from Calbiochem (La Jolla, CA). The antibody against paxillin was from Transduction Laboratories (Lexington, KY), and antibody against RhoB was from Santa Cruz Biotechnology (Santa Cruz, CA). The enhanced chemiluminescence (ECL) Western blotting kit and horseradish peroxidase-conjugated sheep anti-mouse immunoglobulin G (IgG) and anti-rabbit IgG antibodies were purchased from Amersham (Arlington Heights, IL). Genistein was obtained from ICN Biomedical. All other chemicals were obtained from usual commercial sources at the purest grade available. 


\section{Cell Culture}

Rat GEC were developed in a culture system in the laboratories of Drs. W. Couser and K. Bomsztyk and were provided by Dr. C. Richardson (Medical College of Wisconsin, Milwaukee, WI). Cells were grown and maintained in a defined substratum containing collagen type I as previously reported (20). The cells were cultured in 60 - or $100-\mathrm{mm}$ culture plates in $\mathrm{K}_{1}$ media $(47 \%$ HAM's F-12, 47\% DME low glucose, $1 \%$ HEPES, $1.5 \% \mathrm{NaHCO}_{3}, 0.1 \%$ ITS, $1 \%$ L-glutamine, $1 \%$ antibiotic-antimycotic solution to final concentrations of $100 \mathrm{U} / \mathrm{ml}$ penicillin and $100 \mu \mathrm{g} / \mathrm{ml}$ streptomycin) containing $2 \% \mathrm{Nu}$ serum. Culture was performed in a $5 \% \mathrm{CO}_{2}-95 \%$ air atmosphere at $37^{\circ} \mathrm{C}$. At near confluence, cells were washed twice and cultured for $12 \mathrm{hr}$ in $\mathrm{K}_{1}$ media without serum. The morphological and biochemical analysis that followed were therefore performed with cells that were confluent and quiescent. For the measurements of the cellular G- and total actin content and for immunoprecipitation experiments, cells were washed twice with cold phosphate-buffered saline (PBS) and removed from plates using scrapers.

\section{Use of TNF- $\alpha$ and Experimental Design}

In the present study, both human and rat TNF- $\alpha$ were used, which affected equally actin polymerization dynamics in the podocyte culture system studied. Recombinant rat and human TNF- $\alpha$, dissolved in $\mathrm{K}_{1}$ media containing $0.1 \% \mathrm{BSA}$, were introduced in cultured GEC at defined concentrations $(0.1,1,5,10,20 \mathrm{ng} / \mathrm{ml})$ for defined time periods ( $15 \mathrm{~min}, 2 \mathrm{hr}, 4 \mathrm{hr}, 24 \mathrm{hr}$ ). In control incubation experiments, the TNF- $\alpha$ vehicle (Kl media plus $0.1 \%$ BSA) was introduced for identical time periods. In separate experiments, prior to exposure of GEC to TNF- $\alpha$, cells were treated for $40 \mathrm{~min}$ with the protein tyrosine kinase inhibitor genistein (final concentration $100 \mu \mathrm{M}$ ) to explore the relation between TNF- $\alpha$-induced cytoskeletal protein tyrosine phosphorylations and the observed alterations of the actin cytoskeleton. To explore whether an intact cytoskeleton is required for tyrosine phosphorylation of FAK and paxillin by TNF- $\alpha$, cells were pretreated with cytochalasin $\mathrm{B}$, which selectively depolymerizes F-actin to G-actin. In these experiments cytochalasin $\mathrm{B}$ was dissolved in absolute ethanol and introduced in cultured GEC at a final concentration of $1.2 \mu \mathrm{M}$ for $2 \mathrm{hr}$. In control incubation experiments, the cytochalasin B vehicle (absolute ethanol) was introduced for the same time period. At completion of incubations with TNF- $\alpha$, GEC were processed either for measurement of G-actin concentration or for assessment of expression and tyrosine phosphorylation of paxillin and FAK by methods detailed below.

\section{Actin Cytoskeleton Analysis by Confocal Laser Scanning Microscopy}

Morphological assessment of actin cytoskeleton in response to TNF- $\alpha$ was performed by confocal laser scanning microscopy following labeling with rhodamine-phalloidin. GEC were grown for $24 \mathrm{hr}$ on $22 \times 22 \mathrm{~mm}$ coverslips that were collagen I coated in $\mathrm{K}_{1}$ media containing $\mathrm{Nu}$ serum, followed by $12 \mathrm{hr}$ incubation in media without serum. Cells were subsequently incubated for 2 $\mathrm{hr}$ with $10 \mathrm{ng} / \mathrm{ml}$ TNF- $\alpha$. Cell fixation and direct fluorescence staining of microfilaments by rhodamine-phalloidin were performed as previously described (4), except that before mounting the coverslips on glass slides, plastic spacers were attached to the edges of the coverslips to create the appropriate depth for confocal analysis. Specimens were visualized with a confocal laser scanning module attached to an inverted microscope (Zeiss IM 35) equipped with an argon-krypton ion laser as previously described (4).

\section{Direct Fluorescence of Actin Cytoskeleton and Indirect Immunofluorescence}

GEC were grown for $24 \mathrm{hr}$ on gelatin $(0.1 \%)$ coated $22 \times 22 \mathrm{~mm}$ glass coverslips and treated with TNF- $\alpha$ as outlined above. Cell fixation and washing as well as labeling with rhodaminephalloidin or with anti-vinculin and anti-talin antibodies was performed as previously described (6). After the final wash, specimens were mounted on glass slides with slow-fade and were examined with an Olympus BH-2 microscope equipped with epifluorescent illumination. Photomicrographs were obtained with a $35-\mathrm{mm}$ Olympus (C-35AD-4) camera on Kodak P3200 black and white film.

\section{DNase I Inhibition Assay for Determination of Intracellular Actin}

The monomeric (G-) and total actin concentrations in GEC were measured using the DNase I inhibition assay (21), with minor modifications, as previously described (22). Briefly, GEC that were serum starved for $12 \mathrm{hr}$ were washed twice with PBS and lysed on ice with a buffer consist- 
ing of $10 \mathrm{mM} \mathrm{K}_{2} \mathrm{HPO}_{4}, 100 \mathrm{mM} \mathrm{NaF}, 50 \mathrm{mM}$ $\mathrm{KCl}, 2 \mathrm{mM} \mathrm{MgCl}, 1 \mathrm{mM}$ EGTA, $0.2 \mathrm{mM}$ dithiothreitol, $0.5 \%$ Triton $\mathrm{X}-100$, and $1 \mathrm{M}$ sucrose, $\mathrm{pH}$ 7.0. For determination of G-actin concentration, $10 \mu \mathrm{l}$ of the cell lysate was added to an assay mixture containing $10 \mu \mathrm{l}$ of DNase I solution [0.1 $\mathrm{mg} / \mathrm{ml}$ DNase I in $50 \mathrm{mM}$ Tris- $\mathrm{HCl}$ containing 10 mM phenyl methyl sulfonyl fluoride (PMSF) and $0.5 \mathrm{mM} \mathrm{CaCl}_{2}, \mathrm{pH} 7.5$ ] and $1 \mathrm{ml}$ DNA solution $(40 \mu \mathrm{g} / \mathrm{ml}$ DNA in $100 \mathrm{mM}$ Tris- $\mathrm{HCl}$ containing 4

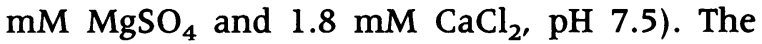
DNase I activity was monitored continuously at $260 \mathrm{~nm}$ in a Perkin-Elmer Lamda 15 doublebeam spectrophotometer. The intracellular actin content was quantified by reference to a standard curve of the inhibition of DNase I activity, constructed with rabbit muscle G-actin, which was isolated as previously described (23). A linear relationship was observed over the range of $25-70 \%$ inhibition of DNase I activity. For measurement of total actin, aliquots of the cell lysate were diluted 2 to 3 times with lysis buffer and then incubated for 20 min on ice with an equal volume of guanidine- $\mathrm{HCl}$ buffer (1.5 M guanidine- $\mathrm{HCl}, 1 \mathrm{M}$ sodium acetate, $1 \mathrm{mM}$ ATP, 20 $\mathrm{mM}$ Tris- $\mathrm{HCl}, \mathrm{pH} 7.5$ ) to depolymerize F-actin to monomeric G-actin. G- and total-actin contents were expressed per total cell protein amount measured colorimetrically (Bio-Rad Protein Assay).

\section{Immunoprecipitation}

Cells were lysed on ice with cold lysis buffer consisting of $50 \mathrm{mM}$ HEPES, pH 7.5, $150 \mathrm{mM}$ $\mathrm{NaCl}, 1.5 \mathrm{mM} \mathrm{MgCl} 2,1 \mathrm{mM}$ EGTA, $10 \%$ glycerol, $1 \%$ Triton $\mathrm{X}-100,1 \mu \mathrm{g} / \mathrm{ml}$ aprotinin, 1 $\mu \mathrm{g} / \mathrm{ml}$ leupeptin, $1 \mathrm{mM}$ PMSF, and $200 \mu \mathrm{M}$ sodium orthovanadate. Cells were scraped off the plates and allowed to lyse for an additional $\mathbf{3 0}$ min on an orbital shaker at $4^{\circ} \mathrm{C}$. Samples were subsequently centrifuged for $30 \mathrm{~min}$ at $14,000 \times$ $g$ at $4^{\circ} \mathrm{C}$ and supernatants were transferred to fresh centrifuge tubes. Protein concentrations were determined with a colorimetric assay (Biorad Protein Assay). Cell lysates containing equal amounts of protein were incubated with either anti-FAK, anti-paxillin, and anti-vinculin monoclonal IgGl or anti-phosphotyrosine monoclonal IgG2bk at $4^{\circ} \mathrm{C}$ overnight. Antigen-antibody complexes formed were then precipitated by agitation for $2 \mathrm{hr}$ at $4^{\circ} \mathrm{C}$ with washed protein-G Sepharose bead slurry. Beads were collected by pulse centrifugation $(14,000 \times g, 5 \mathrm{sec})$ and washed 3 times with lysis buffer. Immunopre- cipitates were solubilized by dissolving in gel sample buffer and boiled for $5 \mathrm{~min}$. Beads were collected by centrifugation and SDS-PAGE was performed with the supernatant fraction.

\section{Immunoblotting}

Immunoprecipitates were run on $4-20 \%$ gradient polyacrylamide gels ( $100 \mathrm{~V}$, constant voltage) and electrophoretically transferred to nitrocellulose paper. A $12 \%$ polyacrylamide gel was used for paxillin and RhoB immunoblotting. Blots were blocked for $1 \mathrm{hr}$ at room temperature with $5 \%$ non-fat dry milk in Tris-buffered saline (TTBS; $10 \mathrm{mM}$ Tris, $\mathrm{pH} 7.5,100 \mathrm{mM} \mathrm{NaCl}, 0.1 \%$ Tween-20) prior to incubation with the anti-FAK or the anti-paxillin monoclonal antibodies. For immunoblotting of RhoB, membranes were blocked for $1 \mathrm{hr}$ at room temperature in $0.05 \%$ Tween-20 in T-TBS containing non-fat dry milk. The nitrocellulose membrane was then probed for $1 \mathrm{hr}$ at room temperature with one of the following antibodies: anti-FAK antibody at 1 $\mu \mathrm{g} / \mathrm{ml}$ in T-TBS; anti-paxillin antibody at 1:4000 in blocking buffer; or anti-RhoB antibody at 1 $\mu \mathrm{g} / \mathrm{ml}$ diluted in blocking buffer. Following incubation, blots were extensively washed with several changes of T-TBS $(0.05 \%$ Tween- 20 for anti-Rho blots). The blots probed with anti-FAK or the anti-paxillin antibodies were incubated for $\mathrm{l} \mathrm{hr}$ at room temperature with horseradish peroxidase-conjugated sheep anti-mouse IgG at 1:5000 (anti-FAK) or 1:2500 (anti-paxillin) and with horseradish peroxidase-conjugated donkey anti-rabbit IgG at 1:2000 (anti-RhoB). Blots were again washed in T-TBS and visualized through enhanced chemiluminescence.

\section{Statistical Analysis}

Results are expressed as the mean $+\operatorname{SEM}(n=$ number of experiments). Statistical analysis of Gand total actin content in GEC was performed by unpaired Student's $t$-test, $p$ values $<0.05$ being considered significant.

\section{Results}

TNF- $\alpha$ Induces Reorganization of Actin Cytoskeleton

To precisely analyze the effect of TNF- $\alpha$ on the actin cytoskeleton of GEC, a confocal laser scanning microscopic analysis was performed. Treatment of GEC with $10 \mathrm{ng} / \mathrm{ml}$ TNF- $\alpha$ for $2 \mathrm{hr}$ resulted in alteration of the overall cell shape, 

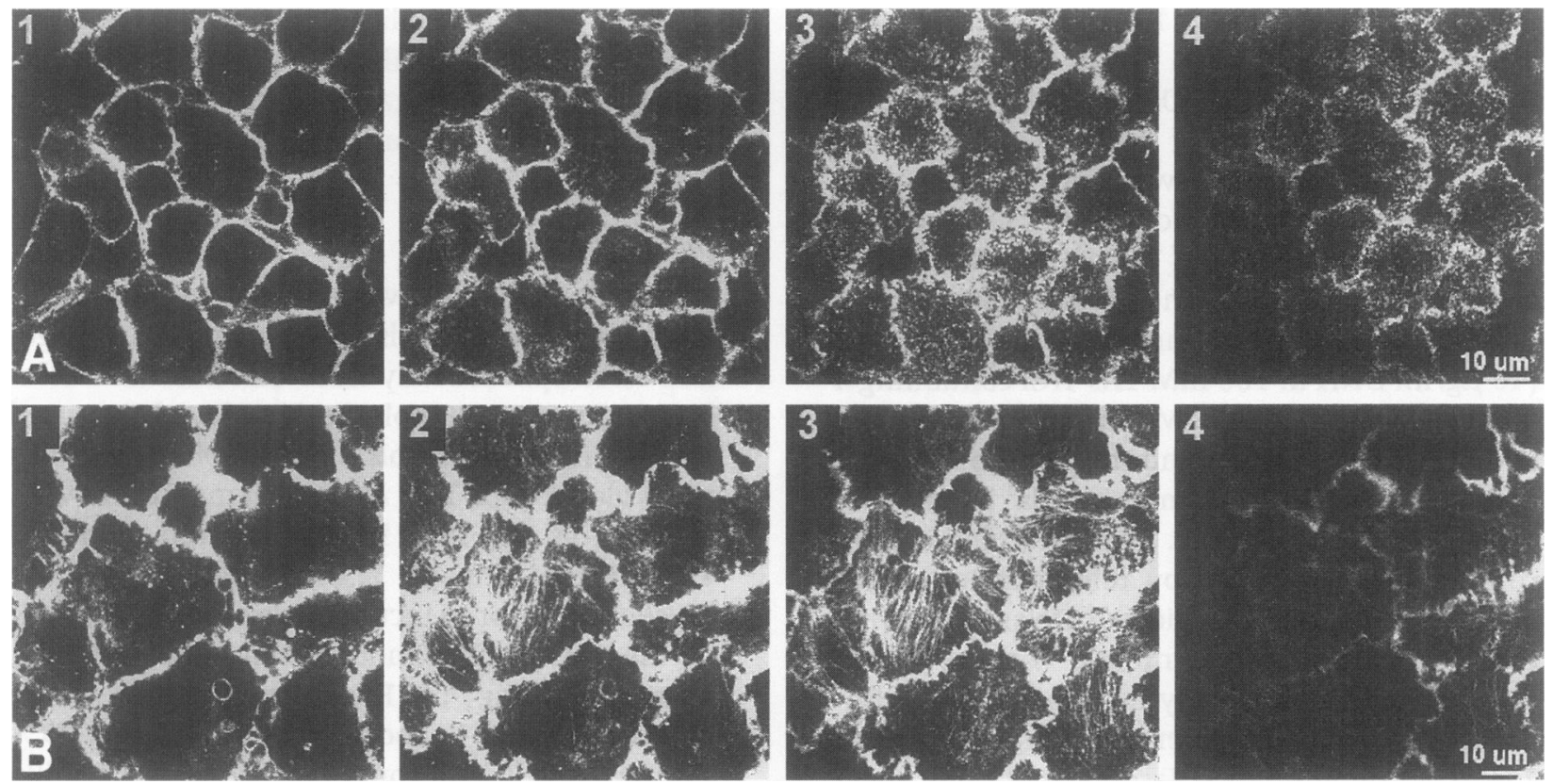

Fig. 1. Confocal laser scanning microscopy of rat glomerular epithelial cells; actin cytoskeleton was stained with rhodamine-phalloidin. (A) Control cells. (B) Cells incubated in the presence of TNF- $\alpha(10 \mathrm{ng} / \mathrm{ml})$ for $2 \mathrm{hr}$. Panels 1-4: Consecutive scanning sections $(0.5 \mu \mathrm{m})$ from the upper cytoplasmic region (1) to the attachment site of the cells (4). Bar $=10 \mu \mathrm{m}$.

which was accompanied by changes in the organization of the actin cytoskeleton (Fig. 1). A relative increase in actin microfilament density and fluorescence, as well as newly formed stress fibers became apparent upon TNF- $\alpha$ treatment, as shown in scanning sections 2 and 3 in Figure 1B. The reorganization effect was evident as early as 15 min after initiation with TNF- $\alpha$ and persisted for as long as $\mathbf{2 4} \mathrm{hr}$ (data not shown).

Because actin stress fibers emanate from focal adhesions, we also examined vinculin, which is a marker protein for the latter structures, in TNF- $\alpha$-treated cells and their lysates. Cells were studied by indirect anti-vinculin immunofluorescence, while their lysates, after anti-phosphotyrosine and anti-vinculin antibody immunoprecipitation, were subjected to electrophoresis and subsequently probed with an anti-vinculin antibody (Fig. 2). Furthermore, since vinculin is known to localize in adherens junctions, in addition to focal adhesions, we verified its sole association with the latter structures by comparing vinculin's topography with that of talin, another actin cytoskeletal protein associated exclusively with focal adhesions. Cells from control incubations revealed marked anti-vinculin and virtually superimposable anti-talin staining (data not shown). Treatment with TNF- $\alpha$ did not alter appreciably the distribution pattern of both proteins or the overall abundance of vinculin, determined by indirect immunofluorescence and immunoprecipitation (Fig. 2), respectively. However, probing of the phosphotyrosine immunoprecipitations with anti-vinculin antibody disclosed an appreciable increment in the tyrosine phosphorylation of this protein following exposure of GEC to TNF- $\alpha$ (Fig. 2). These findings show that TNF- $\alpha$ induces a clear reorganization of actin microfilaments in GEC, which involves the restructuring of the cortical actin network into newly formed stress fibers, and increased tyrosine phosphorylation of the focal adhesion marker vinculin.

\section{TNF- $\alpha$ Induces G- to F-actin Polymerization}

To focus on the mechanism underlying the observed actin cytoskeleton reorganization, we evaluated the ability of TNF- $\alpha$ to induce a shift toward F-actin in the intracellular G-actin pool. For this we used the DNase I inhibition assay to measure cellular levels of G- and total actin and their ratio, the latter representing a well-established quantitative index of G-actin polymerization (4-8). Table 1 summarizes the obtained results: treatment of GEC with $10 \mathrm{ng} / \mathrm{ml}$ of TNF- $\alpha$ for $15 \mathrm{~min}, 2 \mathrm{hr}, 4 \mathrm{hr}$, and $24 \mathrm{hr}$ caused a reproducible and significant $(p<0.05)$ decrease in the 


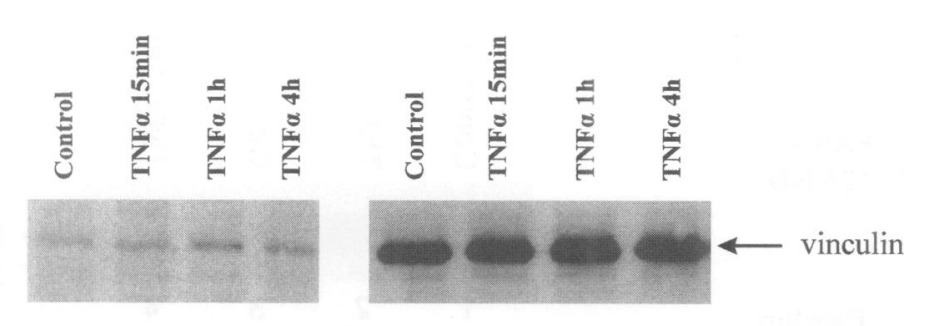

Ip: P-Tyr vinculin
Fig. 2. Tyrosine-phosphorylated proteins and vinculin immunoprecipitated (Ip) with corresponding antibodies from GEC lysates before and after incubation with TNF- $\alpha$ (10 $\mathrm{ng} / \mathrm{ml}$ ) for indicated time periods. After separation of immunoprecipitates on SDS-polyacrylamide gels, proteins were transferred to a nitrocellulose membrane and immunoblotted with monoclonal anti-vinculin antibody. P-Tyr, anti-phosphotyrosine antibody. WB, Western blotting.
G/total-actin ratio by $18 \%, 28 \%, 44 \%$, and $17 \%$, respectively, compared to untreated control cells. It is important to note that total actin content increased considerably upon TNF- $\alpha$-treatment for $24 \mathrm{hr}$, indicating substantial de novo actin biosynthesis (Table 1). G-actin content, on the other hand, decreased within the first $2 \mathrm{hr}$ of incubation, followed by a slight increase. These findings indicate a significant actin polymerization, which is rapidly induced in TNF- $\alpha$-treated GEC and which persists during 24-hr incubations with the cytokine. In experiments (data not shown) we established that the effect of TNF- $\alpha$ on actin microfilament assembly was dose dependent, the most significant drop in G-actin being recorded with $10 \mathrm{ng} / \mathrm{ml}$ of cytokine.

TNF- $\alpha$ Induces Tyrosine Phosphorylation of FAK and Paxillin without Affecting Their Expression Levels

To assess whether FAK and/or paxillin are involved in the cytoskeletal reorganization induced by TNF- $\alpha$, the expression and tyrosine phosphorylation levels of both proteins were monitored. The effect of TNF- $\alpha(10 \mathrm{ng} / \mathrm{ml})$ on FAK and paxillin expression is shown in Fig. 3A. Western blot analysis performed at 2, 5, and $15 \mathrm{~min}$ and 4 $\mathrm{hr}$ following introduction of TNF- $\alpha$ revealed no changes in expression levels of both proteins (Fig. 3A, lanes 1-5). However, during TNF- $\alpha$ treatment, increased levels of tyrosine phosphorylation of FAK became apparent after $2 \mathrm{~min}$ (Fig. 3B, lane 2) and persisted after 5-, and 15min and 4-hr incubations with this cytokine (Fig. 3B, lanes 3-5). Similar results showing extensive TNF- $\alpha$-induced increases in tyrosine phosphorylation levels were obtained for paxillin (Fig. 3B, lanes 2-5).

\section{TNF- $\alpha$ Does Not Alter RhoB Protein Expression}

Since signal transduction pathways leading from receptor activation to actin remodeling seem to involve small GTPases (11-13), we investigated whether Rho family proteins are also involved in

Table 1. Effect of TNF- $\alpha$ on actin polymerization dynamics of GEC

\begin{tabular}{|c|c|c|c|c|c|c|}
\hline & \multirow[b]{2}{*}{$\begin{array}{l}\text { Control } 15 \mathrm{~min} \\
\quad(n=10)\end{array}$} & \multicolumn{4}{|c|}{ TNF- $\alpha$} & \multirow[b]{2}{*}{$\begin{array}{c}\text { Control } 24 \mathrm{hr} \\
(n=5)\end{array}$} \\
\hline & & $\begin{array}{l}15 \text { min } \\
(n=7)\end{array}$ & $\begin{array}{c}2 \mathrm{hr} \\
(n=10)\end{array}$ & $\begin{array}{c}4 \mathrm{hr} \\
(n=9)\end{array}$ & $\begin{array}{c}24 \mathrm{hr} \\
(n=9)\end{array}$ & \\
\hline $\begin{array}{l}\text { G-actin } \\
\qquad(\mu \mathrm{g} / \mathrm{mg})\end{array}$ & $20.67 \pm 0.82$ & $14.45 \pm 1.52$ & $17.9 \pm 1.26$ & $27.03 \pm 2.84$ & $83.71 \pm 4.8$ & $52.70 \pm 5.9$ \\
\hline $\begin{array}{l}\text { Total actin } \\
(\mu \mathrm{g} / \mathrm{mg})\end{array}$ & $41.55 \pm 1.68$ & $35.24 \pm 2.03$ & $50.23 \pm 2.17$ & $96.54 \pm 1.96$ & $209.28 \pm 7.9$ & $109.80 \pm 10.1$ \\
\hline G/total actin & $0.50 \pm 0.03$ & $0.41 \pm 0.01$ * & $0.36 \pm 0.015^{*}$ & $0.28 \pm 0.05^{*}$ & $0.4 \pm 0.025 * \star$ & $0.48 \pm 0.03$ \\
\hline
\end{tabular}

Monomeric $(G)$ and total actin were quantified by the modified DNase I inhibition assay in extracts of untreated (control) or TNF- $\alpha$-treated cells. Actin content is expressed in $\mu \mathrm{g} / \mathrm{mg}$ total cell protein (mean values \pm SEM).

${ }^{*} p<0.05$ versus control at $15 \mathrm{~min}$ and ${ }^{* *} p<0.05$ versus control at $24 \mathrm{hr}$. 


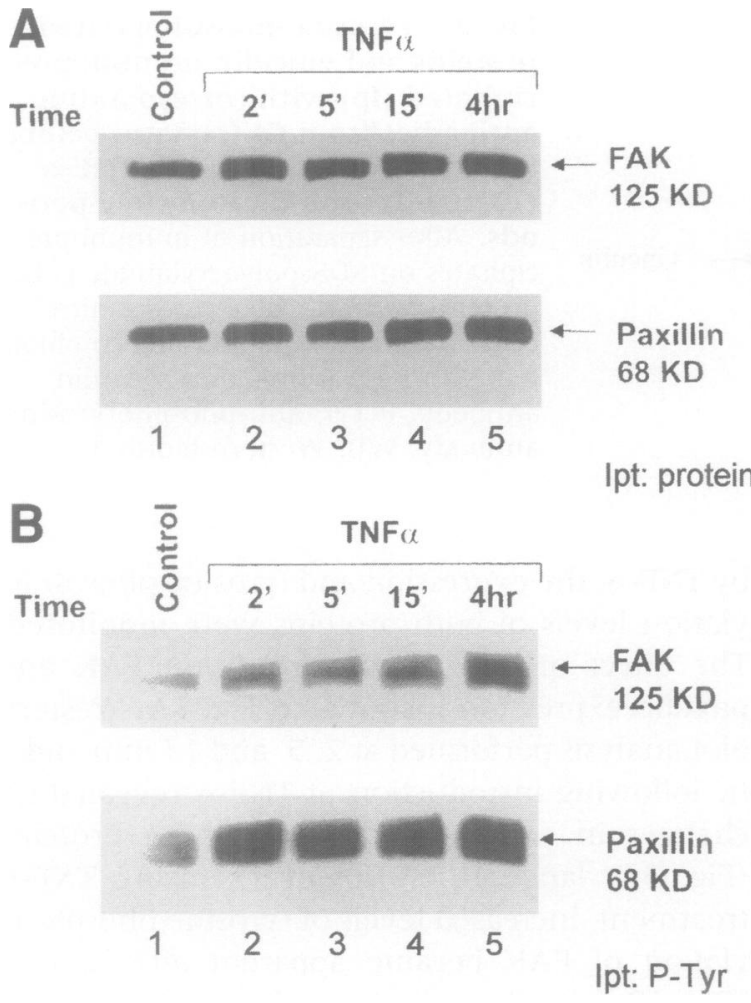

Fig. 3. Western analysis of expression (A) and tyrosine phosphorylation (B) of focal adhesion kinase (FAK) and paxillin. (A) FAK and paxillin were immunoprecipitated with the corresponding anti-FAK and anti-paxillin antibody (Ipt: protein) from GEC that were serum starved overnight and then incubated with TNF- $\alpha(10 \mathrm{ng} / \mathrm{ml})$ for the indicated time periods. After separation of immunoprecipitates on SDS-polyacrylamide gels, proteins were transferred to a nitrocellulose membrane and immunoblotted with monoclonal anti-FAK and anti-paxillin antibodies, respectively. (B) GEC were serum starved overnight and then treated with TNF- $\alpha$ ( 10 $\mathrm{ng} / \mathrm{ml}$ ) for the indicated time periods. Cell lysates were immunoprecipitated with anti-phosphotyrosine antibody (Ipt: P-Tyr). After separation of immunoprecipitates on SDS gels, proteins were transferred to a nitrocellulose membrane and immunoblotted with monoclonal anti-FAK and anti-paxillin antibodies, respectively.

the TNF- $\alpha$-induced actin polymerization observed in our system. As shown in Figure 4, we were unable to document induction of RhoB protein expression in GEC exposed to TNF- $\alpha$. However, this finding does not exclude altered activation of the protein.

Inhibition of Tyrosine Phosphorylation Prevents Reorganization of Actin Cytoskeleton by TNF- $\alpha$

Exposure of GEC to TNF- $\alpha$ in the presence of the tyrosine kinase inhibitor genistein $(100 \mu \mathrm{M})$

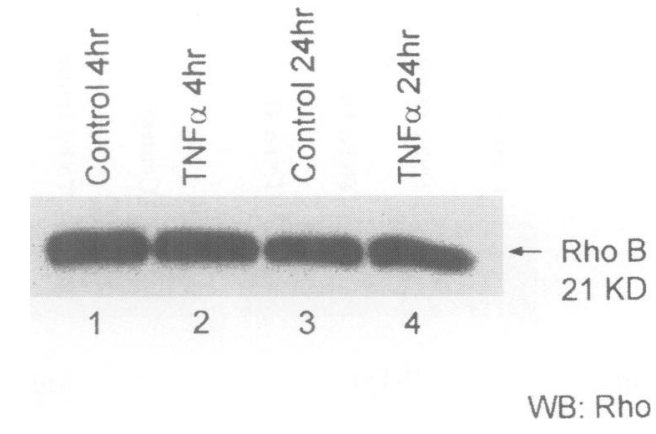

Fig. 4. Effect of TNF- $\alpha$ on RhoB expression after 4-hr and 24-hr exposure to TNF- $\alpha$ of GEC. Cell lysates of untreated and TNF- $\alpha$-treated GEC were subjected to SDS electrophoresis and subsequently proteins were transferred to a nitrocellulose membrane and immunoblotted with polyclonal antiRhoB antibody.

failed to cause changes in the polymerization state of the actin cytoskeleton. Indeed, as shown in separate experiments using the DNase I inhibition assay, the G/total-actin ratio remained unchanged in genistein-pretreated $(40 \mathrm{~min}) \mathrm{GEC}$ after their exposure to TNF- $\alpha$ for 15 and $120 \mathrm{~min}$ $(0.47 \pm 0.021, n=3$ and $0.47 \pm 0.01, n=4$ for 15- and 120-min incubations, respectively, versus $0.47 \pm 0.02, n=4$ for untreated cells). Although the effects of genistein may not be restricted to inhibition of tyrosine kinases, these data suggest the involvement of tyrosine phosphorylation events in the observed actin reorganization by TNF- $\alpha$.

\section{Discussion}

Podocytes possess an extensive cytoskeleton, which, in addition to its framework function for cell body and foot processes, participates in the formation of complex anchoring structures (focal adhesions). These structures are responsible for the attachment of podocytes to the GBM via integrins (24). Podocytes are the targets of injury in several immunologic and toxic human and experimentally induced glomerular diseases, the characteristic functional correlate of which is heavy proteinuria. Morphologic changes of podocytes in responce to injury include foot process flattening and effacement, and microvillous apical membrane transformation and detachment from the GBM (25), all features suggestive of cytoskeletal involvement. Glomeruli from rats with experimental adriamycin or puromycine aminonucleoside-induced nephrosis, in parallel 
with the severity of proteinuria, overproduce TNF- $\alpha$ (26). In patients with membranous nephropathy, TNF- $\alpha$ is overexpressed by visceral glomerular epithelia and urinary concentrations of the cytokine are significantly increased (17). Moreover, TNF- $\alpha$ has been reported to be moderately toxic to GEC in culture, an effect that can be eliminated by treatment with anti-TNF- $\alpha$ antibodies (23).

Our observations demonstrating marked changes in actin cytoskeleton polymerization and in the basement membrane attachment molecules of GEC exposed to TNF- $\alpha$ must therefore be considered against this background. The shift in equilibrium from monomeric (G-) to filamentous (F-) actin indicates microfilament assembly and may reflect attempts at stabilization of the actin cytoskeleton $(4,5,7)$. However, total actin content also increased significantly upon exposure to TNF- $\alpha$ for $24 \mathrm{hr}$ in comparison to control experiments (Table 1), pointing out the induction of actin biosynthesis by this cytokine in GEC. Whereas laser scanning confocal microscopy verified these biochemically derived findings by demonstrating significant actin cytoskeleton reorganization along with the formation of newly synthesized stress fibers, it additionally suggested increases in the volume of TNF- $\alpha$-exposed GEC. Although we have not completed a precise quantitation of this apparent cellular volume increase, we do consider this observation interesting and important, as it appears to be consistent with our group's analogous earlier findings, which suggested the occurrence of concordant increases in actin polymerization and cellular volume in other cellular systems $(8,27)$.

From a pathophysiologic viewpoint, the observation of a GEC volume increase may be relevant to nephropathies characterized by hypertrophy of glomerular podocytes, a response thought to participate in the chain of pathogenetic events eventually leading to segmental glomerulosclerosis $(28,29)$. On the other hand, analogous actin cytoskeleton polymerization responses to TNF- $\alpha$ have been demonstrated in human endothelial cells, which subsequently retract, forming intercellular gaps (30). Endothelial retraction and gap formation have been implicated as contributing to the vascular "leakiness" associated with increased levels of TNF- $\alpha$. Whether the cytoskeletal alterations we observed in glomerular epithelial cells exposed to TNF- $\alpha$ lead to analogous permeability changes is unknown.

Tyrosine phosphorylation is essential for mi- crofilament assembly $(31,32)$. Tyrosine phosphorylation of specific cytoskeletal proteins has also been implicated as a mechanism underlying the assembly of focal adhesions between cells and the extracellular matrix (ECM) (33). Focal adhesions are thought to be important not only as structural links between the ECM and the cytoskeleton but also as sites of signal transduction from the ECM. In our system, TNF- $\alpha$ increased the levels of tyrosine phosphorylation of vinculin without affecting significantly its expression levels or its topography in relation to talin, the latter being known to localize exclusively in focal adhesions. This finding suggests involvement of this focal adhesion molecule in TNF- $\alpha$-induced microfilament redistribution.

Proteins that become phosphorylated on tyrosine in association with microfilament assembly also include FAK and paxillin (34). Increases in FAK and paxillin tyrosine phosphorylation are accompanied by profound alterations in the organization of the actin cytoskeleton and in the assembly of focal adhesions, the distinct areas of the plasma membrane where FAK and paxillin are localized (35). FAK and paxillin are frequently found to colocalize at the termini of F-actin fibers in focal adhesions $(36,37)$. FAK contains a highly conserved tyrosine kinase domain flanked by amino- and carboxyl-terminal noncatalytic domains, the former being the putative integrin-binding site, while the carboxylterminal domain is thought to mediate localization of FAK to focal adhesions and its binding to paxillin (38). Phosphorylation of FAK on tyrosine residues may occur in response to engagement of the integrin receptor with ECM proteins $(34,39-41)$ as well as in response to extracellular signals such as hormones $(41,42)$ and growth factors $(41,43)$. FAK, in turn, phosphorylates paxillin $(44,45)$.

Recent observations suggest that the tyrosine phosphorylation of paxillin may be instrumental in triggering assembly of the actin cytoskeleton and in formation of cytoskeleton-membrane attachments as focal adhesions develop (34). Our observations identify TNF- $\alpha$ as a stimulus for phosphorylation on tyrosine residues of both FAK and paxillin in GEC. This effect mediates the observed assembly and reorganization of the actin cytoskeleton in response to TNF- $\alpha$. In support of this sequence is our finding that genistein largely prevented the TNF- $\alpha$-induced polymerization of actin and redistribution of the microfilaments. Although the effects of genistein may not be restricted to inhibition of tyrosine kinases, 
our findings suggest the involvement of tyrosine phosphorylation events in the observed actin reorganization by TNF- $\alpha(46,47)$. In this regard, the polymerization of $\mathrm{G}$-actin in response to TNF- $\alpha$ observed in our experiments may constitute a mechanism for transduction of signals arising from the TNF- $\alpha$ receptor, which result in tyrosine phosphorylation of FAK in GEC. Such signals may include activation of tyrosine kinases, e.g., MAP kinase (48), that phosphorylate FAK on tyrosine residues (49). Evidence that polymerization of $\mathrm{G}$-actin can serve as a signal transduction mechanism was shown for nerve growth factor (NGF), whose receptor belongs to the TNF/NGF receptor superfamily. Thus, NGF was reported to induce a rapid increase in tyrosine phosphorylation of paxillin and this effect was blocked by cytochalasin $\mathrm{D}$, which disrupts cytoskeletal assembly $(50,51)$. In line with these reports are experiments in GEC showing that cytochalasin B largely abrogated tyrosine phosphorylation of FAK and paxillin in response to TNF- $\alpha$-treated GEC (data not shown). This finding may indicate that an intact actin cytoskeleton is required for the transmission of signals arising from TNF- $\alpha$ receptor activation and support the notion that rapid actin cytoskeleton redistribution may be an important step in the mechanism controlling the signal transduction pathway of the TNF- $\alpha$ response. The apparent synchrony of focal adhesion and stress fiber formation suggests that actin polymerization and focal adhesion assembly may represent distinct downstream effects of a common regulatory molecule, such as the small GTP-binding protein of the ras superfamily, Rho (11-13,52,53). In an attempt to address this issue, we were unable to document induction of RhoB protein expression in cells exposed to TNF- $\alpha$, which does not exclude alterations in the activation of the protein.

In summary, our observations demonstrate that in GEC, TNF- $\alpha$ induces events that appear to be linked and are fundamental in cytoskeletal organization and signaling, including $(a)$ restructuring of actin cytoskeleton and enhanced actin biosynthesis and polymerization of G-actin, and (b) tyrosine phosphorylation of FAK, paxillin, and vinculin. In view of the importance of these phenomena in the attachment of cells to their substratum, our findings suggest that the observed TNF- $\alpha$-GEC-cytoskeleton interactions may be relevant to the pathogenesis of proteinuric glomerupathies, in which increased glomerular expression of TNF- $\alpha$ is associated with perturbed podocyte attachment to the GBM.

\section{Acknowledgments}

We thank Prof. Dr. Peter Traub, Max-PlanckInstitute for Cell Biology, Ladenburg, Germany, for allowing us the use of the confocal laser scanning microscopy facilities. We also thank the members of the Biochemistry Department for excellent technical assistance and useful comments on this paper. This work was supported by grants from the General Secretariat of Research and Technology of Greece (EKBAN and YIIEP).

\section{References}

1. Kashgarian M. (1997) Morphologic evaluation of immune renal disease. In: Neilson EG, Couser WG (eds). Immunologic Renal Diseases. Lippincott-Raven, Philadelphia, pp. 837-860.

2. Gumbiner BM. (1993) Proteins associated with the cytoplasmic surface of adhesion molecules. Neuron 11: 551-564.

3. Burridge K, Fath K, Kelly T, Nuckolls G, Turner C. (1988) Focal adhesions: transmembrane junctions between the extracellular matrix and the cytoskeleton. Annu. Rev. Cell Biol. 4: 487-525.

4. Koukouritaki SB, Theodoropoulos PA, Margioris AN, Gravanis A, Stournaras C. (1996) Dexamethasone alters rapidly actin polymerization dynamics in human endometrial cells: evidence for nongenomic action involving cAMP turnover. J. Cell. Biochem. 62: 251-261.

5. Koukouritaki SB, Margioris AN, Gravanis A, Hartig R, Stournaras C. (1997) Dexamethasone induces rapid actin assembly in human endometrial cells without affecting its synthesis. J. Cell. Biochem. 65: 492-500.

6. Papakonstanti EA, Emmanouel DS, Gravanis A, Stournaras C. (1996) $\mathrm{Na}^{+} / \mathrm{Pi}$ co-transport alters rapidly cytoskeletal protein polymerization dynamics in opossum kidney cells. Biochem. J. 315: 241-247.

7. Papakonstanti EA, Bakogeourgou E, Castanas E, Emmanouel DS, Hartig R, Stournaras C. (1998) Early alterations of actin cytoskeleton in OK Cells by opioids. J. Cell. Biochem. 70: 60-69.

8. Moustakas A, Theodoropoulos PA, Gravanis A, Häussinger D, Stournaras C. (1998) The cytoskeleton in cell volume regulation. Contrib. Nephrol. 123: 121-134.

9. Kreis T, Vale R. (eds). (1993) Guidebook to the Cytoskeletal and Motor Proteins. Oxford University Press, Oxford.

10. Craig SW, Johnson RP. (1996) Assembly of focal adhesions: progress, paradigms and portents. Curr. Opin. Cell. Biol. 8: 74-85.

11. Ridley AJ, Hall A. (1992) The small GTP-binding protein rho regulates the assembly of focal adhesions and actin stress fibers in response to growth factors. Cell 70: 389-399. 
12. Tapon N, Hall A. (1997) Rho, rac and cdc42 GTPases regulate the organization of the actin cytoskeleton. Curr. Opin. Cell. Biol. 9: 86-92.

13. Moustakas A, Stournaras C. (1999) Regulation of actin organization by TGF- $\beta$ in $\mathrm{H}$-ras transformed fibroblasts. J. Cell Sci. 112: 1169-1179.

14. Camussi G, Mariano F, Biancone L, Montrucchio G, Vercellone A. (1993) Effect of cytokines on the cytoskeleton of resident glomerular cells. Kidney Int. 43 (Suppl. 39): S32-S36.

15. Wardle N. (1993) Minimal change nephropathy: how does the immune system affect the glomerulus? Nephrol. Dial. Transplant. 8: 787.

16. Savin VJ, Sharma R, Sharma MS, et al. (1996) Circulating factor associated with increased glomerular permeability to albumin in recurrent focal segmental glomerulosclerosis. N. Engl. J. Med. 334: $878-883$.

17. Neale TJ, Ruger BM, Macaulay $H$, et al. (1995) Tumor necrosis factor- $\alpha$ is expressed by glomerular viscelar epithelial cells in human membranous nephropathy. Am. J. Pathol. 146: 1444-1454.

18. Tabibzadeh S, Kong QF, Kapur S, Satyaswaroop PG, Aktories K. (1995) Tumor necrosis factor- $\alpha$ mediated dyscohesion of epithelial cells is associated with disordered expression of cadherin $/ \beta$ catenin and disassembly of actin filaments. Hum. Reprod. 10: 994-1004.

19. Liu ZY, Ganju RK, Wang J-F, et al. (1997) Cytokine signalling through the novel tyrosine kinase RAFTK in Kaposi's sarcoma cells. J. Clin. Invest. 99: 1798-1804.

20. Richardson CA, Gordon KL, Couser WG, Bomsztyk K. (1995) IL-1 beta increases laminin B2 chain mRNA levels and activates NF-kappa B in rat glomerular epithelial cells. Am. J. Physiol. 268: F273-F278.

21. Blikstad I, Markey F, Carlsson L, Person T, Lindberg U. (1978) Selective assay of monomeric and filamentous actin in cell extracts, using inhibition of deoxyribonuclease I. Cell 15: 935-943.

22. Katsantonis J, Toska A, Koukouritaki SB, Theodoropoulos PA, Gravanis A, Stournaras C. (1994) Differences in the G/total actin ratio and microfilament stability between normal and malignant human keratinocytes. Cell Biochem. Funct. 12: 267274.

23. Faulstich $\mathrm{H}$, Merkler I, Blackholm H, Stournaras C. (1984) Nucleotide in monomeric actin regulates the reactivity of the thiol groups. Biochemistry 23: 1608-1612.

24. Drenckhahn D, Franke RP. (1998) Ultrastructural organization of contractile and cytoskeletal proteins in glomerular podocytes of chicken, rat and man. Lab. Invest. 59: 673-682.

25. Kerjashki D. (1994) Dysfunction of cell biological mechanisms of visceral epithelial cells (podocytes) in glomerular diseases. Kidney Int. 45: 300-313.

26. Gomez-Chiarri M, Ortiz A, Lerma JL, et al. (1994) Involvement of tumor necrosis factor and platelet activating factor in the pathogenesis of experimental nephrosis in rats. Lab. Invest. 70: 449-459.

27. Theodoropoulos PA, Stournaras C, Stoll B, et al. (1992) Hepatocyte swelling leads to rapid decrease of the G-/total actin ratio and increases actin mRNA levels. FEBS Lett. 311: 241-245.

28. Rennke HG. (1994) How does glomerular epithelial cell injury contribute to progressive glomerular damage? Kidney Int. 45 (Suppl. 45): S58-S63.

29. Kriz W, Elger $M$, Nagata $M$, et al. (1994) The role of podocytes in the development of glomerular sclerosis. Kidney Int. 45 (Suppl. 45): S64-S72.

30. Wojciak-Scothard B, Entwistle A, Garg R, Ridely AJ. (1998) Regulation of TNF-alpha-induced reorganization of the actin cytoskeleton and cellcell junctions by Rho, Rac, and Cdc 42 in human endothelial cells. J. Cell. Physiol. 176: 150-165.

31. Melamed I, Downey GP, Roifman CM. (1991) Tyrosine phosphorylation is essential for microfilament assembly in B-lymphocytes. Biochem. Biophys. Res. Commun. 176: 1424-1429.

32. Pumiglia KM, Lau L-F, Huang C-K, Burroughs S, Feinstein MB. (1992) Activation of signal transduction in platelets by the tyrosine phosphatase inhibitor pervanadate (vanadyl hydroperoxide). Biochem. J. 286: 441-449.

33. Chrzanowska-Wodnicka M, Burridge K. (1994) Tyrosine phosphorylation is involved in reorganization of the actin cytoskeleton in response to serum or LPA stimulation. J. Cell Sci. 107: 36433654.

34. Burridge K, Turner CE, Romer LH. (1992) Tyrosine phosphorylation of paxillin and ppl $25^{\mathrm{FAK}}$ accompanies cell adhesion to extracellular matrix: a role in cytoskeletal assembly. J. Cell Biol. 119: 893-903.

35. Seufferlein T, Rozengurt E. (1995) Sphingosylphosphorylcholine rapidly induces tyrosine phosphorylation of $\mathrm{p} 125^{\mathrm{FAK}}$ and paxillin, rearrangement of the actin cytoskeleton and focal contact assembly. J. Biol. Chem. 270: 24343-24351.

36. Turner CE, Glenney JR, Burridge K. (1990) Paxillin: a new vinculin-binding protein present in focal adhesions. J. Cell Biol. 111: 1059-1068.

37. Tachibana K, Sato T, D'Avirro N, Morimoto C. (1995) Direct association of pp125 $5^{\text {FAK }}$ with paxillin, the focal adhesion-targeting mechanism of ppl25 ${ }^{\mathrm{FAK}}$. J. Exp. Med. 182: 1089-1 100.

38. Schaller MD, Parsons JT. (1994) Focal adhesion kinase and associated proteins. Curr. Opin. Cell Biol. 6: 705-710.

39. Lipfert L, Haimovich B, Schaller MD, Cobb BS, Parsons JT, Brugge JS. (1992) Integrin-dependent phosphorylation and activation of the protein tyrosine kinase ppl25 $25^{\mathrm{FAK}}$ in platelets. J. Cell Biol. 119: 905-912.

40. Clark EA, Brugge JS. (1995) Integrins and signal transduction pathways: the road taken. Science 268: $223-239$. 
41. Rozengurt E. (1995) Convergent signaling in the action of integrins, neuropeptides, growth factors and oncogenes. Cancer Surv. 24: 81-96.

42. Zachary I, Sinnett-Smith J, Turner CE, Rozengurt E. (1993) Bombesin, vasopressin, and endothelin rapidly stimulate tyrosine phosphorylation of the focal adhesion-associated protein paxillin in Swiss 3T3 cells. J. Biol. Chem. 268: 22060-22065.

43. Rankin S, Rozengurt E. (1994) Platelet-derived growth factor modulation of focal adhesion kinase $\left(\mathrm{ppl} 25^{\mathrm{FAK}}\right)$ and paxillin tyrosine phosphorylation in Swiss 3T3 cells. J. Biol. Chem. 269: 704-710.

44. Turner CE, Schaller MD, Parsons JT. (1993) Tyrosine phosphorylation of the focal adhesion kinase pp $125^{\mathrm{FAK}}$ during development: relation to paxillin. J. Cell Sci. 105: 637-645.

45. Bellis SL, Miller JT, Turner CE. (1995) Characterization of tyrosine phosphorylation of paxillin in vitro by focal adhesion kinase. J. Biol. Chem. 270: 17437-17441.

46. Akiyama T, Ogawara H. (1991) Use and specificity of genistein as inhibitor of protein-tyrosine kinases. Methods Enzymol. 201: 362-370.

47. Yap AS, Keast JR, Manley SW. (1994) Thyroid cell spreading and focal adhesion formation depend upon protein phosphorylation and actin microfilaments. Exp. Cell Res. 210: 306-314.

48. Rafiee P, Lee JK, Leung CC, Raffin TA. (1995) TNF- $\alpha$ induces tyrosine phosphorylation of mitogen-activated protein kinase in adherent human neutrophils. J. Immunol. 154: 4785-4792.

49. Yamada KM, Geiger B. (1997) Molecular interactions in cell adhesion complexes. Curr. Opin. Cell Biol. 9: 76-85.

50. Khan MA, Okumura N, Okada M, Kobayashi S, Nakagawa H. (1995) Nerve growth factor stimulates tyrosine phosphorylation of paxillin in PC12h cells. FEBS Lett. 362: 201-204.

51. Melamed I, Turner CE, Aktories K, Kaplan DR, Gelfand EW. (1995) Nerve growth factor triggers microfilament assembly and paxillin phosphorylation in human B lymphocytes. J. Exp. Med. 181: 1071-1079.

52. Rosales C, O'Brien V, Kornberg L, Juliano R. (1995). Signal transduction by cell adhesion receptors. Biochim. Biophys. Acta 1242: 77-98.

53. Flinn HM, Ridley AJ. (1996) Rho stimulates tyrosine phosphorylation of focal adhesion kinase, pl 30 and paxillin. J. Cell Sci. 109: 1133-1141. 